\title{
IMPLEMENTASI CONTINOUS QUALITY IMPROVEMENT DALAM MANAJEMEN PERPUSTAKAAN Di AZ-ZAINIYAH PONDOK PESANTREN NURUL JADID
}

Nur Diana Holdah

\author{
Univesitas Nurul Jadid \\ Manajemen pendidikan islam \\ Email : dianakhalidah41@gmail.com
}

\begin{abstract}
$\underline{\text { ABSTRAk }}$
$\underline{\text { Pada dasarnya manajemen perpustakaan adalah proses untuk mengoptimalkan kontribusi }}$ manusia, material, dan anggaran untuk mencapai tujuan perpustakaan. Perpustakaan Azzainiyah Pondok Pesantren Nurul Jadid (Dalbar) masih mengalami beberapa hambatan sehingga belum bisa berjalan dengan semestinya. Hambatan tersebut terletak pada pengelolaan perpustakaan tersendiri. Dengan Implementasi continous Quality improvement Dalam Manajemen perpustakaan di Az-zainiyah Pondok Pesantren Nurul Jadid, pengelolaan perpustakaan terjadi perbaikan ulang untuk menjadikan perpustakaan tersebut lebih baik dari sebelumnya dari segi tatanan ruang, penambahan bahan koleksi pustaka dan lain sebagainya. Dengan pengelolaan tersebut, perpustakaan Az-zainiyah mampu menambah bahan koleksi pustaka dua kali pertahunnya dengan menyesuaikan kebutuhan santri di Pondok Pesantren Nurul Jadid itu sendiri. Juga untuk menarik minat para santri untuk mengunjungi perpustakaan dengan membaca buku atau majalah-majalah yang tersedia, bertujuan untuk menambah wawasan dan memiliki pengetahuan atau informasi baru bagi santri wilayah Azzainiyah Pondok Pesantren nurul Jadid.
\end{abstract}




\section{A. Pendahuluan}

Perkembnagan dan pemanfaatan teknologi sudah menyatu daalam kehidupan masyarakat sehingga dapat memberikan kemudahan dalam mendapatkan informasi yang dibutuhkan. Perpustakaan sebagai pusat informasi memiliki peran yang sangat penting dalam menyebarkankan ilmu pengetahuan kepada pemakainya. Perpustakaan sebagai lembaga pendidikan dan lembaga penyedia informasi akan memilki kinerja yang apabila mempunyai manajemen yang memadai, sehingga seluruh aktifitas lembaga akan mengarah pada upaya pencapaian tujuan yang direncanakan.

Implementasi Continous Quality Improvement yakni pengelolaan perpustakaan. Pengelolaan merupakan sebuah proses dalam melakukan sesuatu dengan menjadikan sebuah pergerakan kepada orang lain. ${ }^{1}$ Selain itu pengelolaan perpustakaan adalah suatu proses kegiatan yang ada di perpustakaan yang meliputi kegiaatan mulai dari pengelolaan sampai dengan pelayanan pengguna perpustakaan. ${ }^{2}$ Perpustakaan yang ada bukan hanya sebagai tempat penyimpanan, peminjaman, dan pengumpulan berbagai refrensi, tapi juga sebagai penunjang tercapainya tujuan pendidikan dan sebagai pembantu guru dan murid dalam melaksanakan tugastugasnya.

Manajemen adalah suatu proses dalam pencapaian sasaran-sasaran tujuan yang terencana, terorganisir, menggerakkan, menggerakkan, dan pengawasan dari semua kegiatan dan sumber-sumber yang dimiliki. Pada hakikatnya manajemen adalah suatu untuk mencapai tujuan melalui kerja orang-orang lain. Secara lebih terperinci dapat dinyatakan bahwa manajemen meliputi perancangan dan sifat-sifat usaha kelompok dalam rangka untuk mencapai tujuan. ${ }^{3}$

Secara umum perpustakaan adalah tempat untuk mencari informasi-informasi yang di dalamnya terdapat beberapa kumpulan buku dan referensi lainnya yang bisa

\footnotetext{
${ }^{1}$ KBBI / Arif Surachman, Pengelolaan perpustakaan, Artikel 2005, 3

2 Winda sari, Marlini, Penerapan Fungsi ManajemenDalam Penegelolaan PerpustakaanDi SMK Tamansiswa Padang, Jurnal Informasi Perpustakaan Dan Kearsipan vol.1 No. 1 September 2012, Seri A, Diakses Pada tanggal 3 Mei 2018

3 I Ketut Widiasa, Manajemen Perpustakaan Sekolah, Jurnal Perpustakaan Sekolah, Diakses Pada Tanggal 3 Mei 2018
} 
dijadikan bahan dalam proses pembelajaran. Sehingga, terdapat manajemen perpustakan yang harus diperhatikan untuk memaksimalkan pelayanan yang terdapat diperpustakan dan membuat pelanggan merasa nyaman untuk mencari sumber informasi yang ada di perpustakaan. Dalam undang-undang perpustakaan disebutkan bahwa perpustakaan adalah institusi pengelola koleksi karya tulis, karya cetak, atau karya rekam secara professional dengan sistem yang baku guna memenuhi kebutuhan pendidikan, penelitian, pelestarian, informasi, dan rekreasi para pemustaka. ${ }^{4}$

Perpustakaan Az-zainiyah Pondok Pesantren Nurul Jadid (Dalbar) adalah salah satu media bagi santri untuk mendapatkan informasi dan sebuah pengetahuan baru yang ada di pesantren. Serta santri juga dapat mengetahui tentang perkembangan dunia luar melalui media Koran yang tersedia diperpustakaan Az-zainiyah Pondok Pesantren Nurul Jadid.

Manajemen perpustakaan adalah pengelolaan perpustakaan yang didasarkan kepada teori dan prinsip manajemen. Salah satu bentuk pengelolaan perpustakaan adalah pengembangan. ${ }^{5}$ Yakni yang perlu dikembangan oleh perpustakaan adalah koleksi, sumber daya manusia, masyarakat pemakai, dan sistem layanan.

B. Implementasi Continous Quality Improvement Dalam Majaemen Perpustakaan

Perpustakaan berkembang dari waktu ke waktu. Perkembangan tersebut menjadi pesat karena menyesuaikan dengan kebutuhan dan pengetahuan manusia. Perkembangan tersebut bisa dilihat dari pola kehidupan manusia dan teknologi informasi. Oleh karena itu, ada berbagai macam perpustakaan yang menyesuaikan dengan pola kehidupan, pengetahuan, dan kebutuan manusia itu sendiri. Berikut adalah jenis-jenis perpustakaan yang perlu diketahui, diantaranya :

\section{Perpustakaan Nasional}

\footnotetext{
${ }^{4}$ M. Reza Rokan, Manajemen Perpustakaan sekolah, Jurnal Iqra' Volume 11 No 01, Diakses Pada Tanggal 3 Mei 2018

5 Fitwi Luthfiyah, Manajemen PerpustakaanDalam Meningkatkan Layanan Perpustakaan, Jurnal elIdare, vol.1, No.2, Diakses Pada tanggal 2 Mei 2018
} 
Perpustakaan ini adalah perpustakaan yang didirikan di ibu kota yang juga merupakan induk dari semua perpustakaan yang ada, baik perpustakaan umum, khusus, sekolah, dan juga perguruan tinggi. Di Indonesia, perpustakaan nasional ini bertempat di kota Jakarta. Perpustakaan nasional ini berfungsi sebagai:

a. Pusat referensi nasional yang mampu menjawab semua pertanyaan tentang Indonesia.

b. Perpustakaan deposit yang menyimpan seluruh pustaka hasil terbitan Indonesia atau luar negeri.

c. Badan penerbit Bibliografi

2. Perpustakaan Umum ${ }^{6}$

Perpustakaan umum adalah perpustakaan yang didirikan untuk masyarakat umum tanpa melihat latar belakang kehidupan masyarakat tersebut yang bertujuan untuk:

a. Pusat informasi kebutuhan masyarakat baik kebutuhan refrensi dan pengisi waktu luang.

b. Tempat pemeliharaan tentang tulisan kebudayaan masa lampau dan kini sebagai pengembang budaya mendatang.

3. Perpustakaan Khusus

Merupakan sebuah perpustakaan yang didirikan untuk mendukung visi, misi, dan tujuan instansi khusus yang bersangkutan. Fungsi perpustakaan ini adalah sebagai pusat informasi yang berhubungan dengan penelitian dan pengembangan.

4. Perpustakaan Sekolah ${ }^{7}$

Ini adalah perpustakaan yang didirikan oleh sekolah untuk masyarakat sekolah itu sendiri.

5. Perpustakaan Perguruan Tinggi

\footnotetext{
${ }^{6}$ Wikipedia. 2012. Definisi Perpustakaan. www.wikipedia.com diakses pada tanggal 2 Mei 2018.

${ }^{7}$ https://sites.google.com/site/seputarilmuperpustakaan/jenis-jenis-perpustakaan. diakses pada tanggal 2
} Mei 2018 
Perpustakaan perguruan tinggi yaitu perpustakaan yang didirikan untuk mengumpulkan, memelihara, menyimpan, mengatur, mengawetkan dan menggunakan bahan pustakanya sebagai penunjang pendidikan.

Pengelolaan merupakan sebuah proses dalam melakukan sesuatu dengan menjadikan sebuah pergerakan kepada orang lain. Perpustakaan yang ada bukan hanya sebagai tempat penyimpanan, peminjaman, dan pengumpulan berbagai refrensi, tapi juga sebagai penunjang tercapainya tujuan pendidikan dan sebagai pembantu guru dan murid dalam melaksanakan tugas-tugasnya.

Pengelolaan perpustakaan biasanya menyesuaikan dengan jenis perpustakaannya, idealnya layanan yang biasa dilakukan antara lain: ${ }^{8}$

1. Gedung atau ruangan

Hal pertama yang harus dilakukan dalam pengelolaan perpustakaan adalah melihat bagaimana gedungnya baik dari segi besar tidaknya ruangan, tempat atau lokasi ruangan yang akan dijadikan perpustakaan, dan pemeliharaan perpustakaan.

Dari segi besar tidaknya, bisa ditentukan dengan ada berapa jumlah murid yang ada di sekolah tersebut. Semakin banyak jumlah murid yang ada maka akan semakin luas pula ruangan perpustakaan yang ada.

Pemilihan lokasi yang tepat dapat berimbas kepada efektif tidaknya pelaksanaan pembelajaran. Misalnya, ada ruang perpustakaan yang biasanya tenang dan tentram tapi letaknya berdampingan dengan ruang kantin, maka hal tersebut dapat mengakibatkan hilangnya konsentrasi belajar para murid dalam perpustakaan.

Pemeliharaan perpustakaan akan menjadi perhatian utama saat pertama memasuki sebuah perpustakaan, jika ruangannya tertata dengan baik maka para pembaca akan merasa nyaman jika haris berlama-lama dalam ruangan tersebut.

2. Peralatan dan perlengkapan

Kelengkapan peralatan dan perlengkapan yang ada merupakan penunjang bagi baik dan tidaknya sebuah perpustakaan. Semakin lengkap

\footnotetext{
${ }^{8}$ Muhammad Kharits M, Pengelolaan Perpustakaan Sebagai Sumber Belajar di Sd Negeri 1 Pogung Kecamatan Cawas Kabupaten Klaten, Artikel Jurnal 2015, 4-8. Diakses Pada 2 Mei 2018.
} 
peralatan dan perlengkapan yang ada akan memudahkan proses pelayanan pada pengunjung perpustakaan.

Dalam peralatan dan perlengkapan perpustakaan ini, dapat dibedakan menjadi dua, yaitu peralatan yang habis pakai dan tahan lama. Peralatan yang habis pakai itu seperti pensil, pen, kartu buku, kartu peminjaman, kartu anggota, formulir pendaftaran anggota, dan lain-lain, sedangkan peralatan yang tahan lama itu seperti gunting, silet, stempel, bantal stempel, penggaris pelubang kertas, jam dinding, kotak surat, kotak sampah dan lain sebagainya.

3. Tata ruang perpustakaan

Penataan yang tepat akan menjadikan perpustakaan tersebut menjadi tempat yang bersahabat. Penataan ini sangatlah berguna untuk semua rakyat perpustakaan, jika penataannya baik maka akan baik pula pelayanan serta pekerjaan-pekerjaan yang terjadi di dalamnya.

Peletakan meja dan rak buku yang berdekatan bisa membuat para warga perpustakaan terhalangi untuk mengambil dan membaca koleksi bahan pustaka. Dalam tatanan perpustakaan juga diperlukan sirkulasi udara dan cahaya yang tepat guna memudahkan para warga perpustakaan untuk bernapas serta tidak membuat para pembaca menjadi lelah dalam pengelihatan.

4. Koleksi bahan pustaka

Dalam hal ini para pustakawan atau pengelola perpustakaan bisa mengecek apa saja yang ada di perpustakaan dari koleksi buku cetak fiksi dan non-fiksi, majalah, karya ilmiah, kitab-kitab sampai koleksi barang audio visual. ${ }^{9}$ Hal ini bertujuan untuk memudahkan penataan buku-buku yang ada.

Untuk memudahkan pekerjaan para pustakawan hendaknya para pustakawan mengetahui hal apa saja yang harus dilakukan dalam koleksi bahan pustaka. $^{10}$ Hal pertama yang biasanya dilakukan oleh para

\footnotetext{
${ }^{9}$ Hafid Alrosyid, Pengadaan Bahan Pustaka di Perpustakaan Universitas Muhammadiyah Surakarta, Tugas Akhir, Surakarta: 2008, 28. Diakses Pada Tanggal 2 Mei 2018.

${ }^{10}$ Anugrahangraini, Sistem Pengelolaan Bahan Pustaka, Skripsi, Makasar, 2015, 23-26. Diakses pada tanggal 2 Mei 2018.
} 
pustakawan adalah inventarisasi sebagai pencatat barang milik perpustakaan. Kedua, pemberian stempel pada buku sebagai bukti keabsahan pemilik. Ketiga, pemberian nomor buku guna mengetahui sudah berapa banyakkah buku yang ada, dan lain sebagainya.

5. Tenaga perpustakaan

Tanpa adanya sumber daya maka pengelolaan tidak akan terjalankan. Oleh karena itu, dalam sebuah perpustakaan sangatlah membutuhkan tenaga perpustakaan atau pustakawan untuk mengelola sebuah perpustakaan. ${ }^{11}$

Dalam perpustakaan pastilah terjadi sebuah layanan yang nantinya akan dilaksanakan oleh para pustakawan. Pustakawan yang berkualitas sangatlah berguna untuk mengoptimalkan layanan-layanan yang terjadi dalam perpustakaan. ${ }^{12}$ Oleh karenanya, dalam perpustakaan membutuhkan para pustakawan yang memiliki wawasan tentang perpustakaan, kepribadian yang ramah, luwes dan menarik juga memiliki tehnik komunikasi yang baik.

6. Biaya

Bagus tidaknya sebuah perpustakaan tergantung seberapa dana yang dimilikinya, jika besar maka akan baguslah perpustakaan tersebut tapi jika tidak maka sebaliknya yang akan terjadi. Dana perpustakaan ini biasanya bisa didapat melalui dana yang diberikan oleh pemerintah, tapi tidak menutup kemungkinan jika hanya dana dari pemerintah saja yang didapat akan bisa mencukupi kebutuhan-kebutuhan perpustakaan. Oleh karena itu, biaya pengelolaan juga merupakan hal penting yang harus diperhatikan.

7. Pelayanan perpustakaan

Pelayanan perpustakaan ini bisa terealisasi dengan baik karena adanya pustakawan yang berkualitas seperti yang telah dijelaskan dalam sub bab sebelumnya. Pada umumnya, layanan perpustakaan terdiri dari layanan

\footnotetext{
11 Muhammad Kharits Ma'sum, Pengelolaan Perpustakaan Sebagai Sumber Belajar di SD Negeri 1 Pogung Kecamatan Cawas Kabupaten Klaten, Skripsi, Yogyakarta, Januari, 35. Diakses pada tanggal 2 Mei 2018.

12 Erma Awalien Rochmah, Pengelolaan Layanan Perpustakaan, Jurnal Ta'allum, Vol 4:2, 2016, 283. Diakses Pada Tanggal 2 Mei 2018.
} 
teknis dan layanan pengguna. ${ }^{13}$ Layanan teknis ini biasanya meliputi bagian pengembangan, pengolahan dan administrasi yang ada dalam perpustakaan, sedangkan layanan pengguna itu bisa berupa peminjaman koleksi, layanan refrensi dan lain-lain.

8. Tata Tertib perpustakaan

Dalam hidup tentunya ada yang namanya aturan, karena tanpa adanya peraturan tersebut sebuah pekerjaan tidaklah akan berjalan dengan efektif bila tidak mematuhi peraturan tersebut.

C. Analisis Implementasi Continous Quality Improvement Dalam Manajemen Perpustakaan.

Sebagaimana yang kita ketahui memiliki perpustakaan yang ideal membutuhkan manajemen perpustakaan yang memadai, dengan melihat beberapa pengelolaan perpustakaan diatas.

Sejauh ini perpustakaan Az-zainiyah pondok Pesantren Nurul Jadid menerapkan pengelolaan yang tertera diatas, sehingga perpustakaan Az-zainiyah Pondok Pesantren Nurul jadid mampu menarik minat santri untuk membaca. Dengan bahan koleksi yang lebih banyak dari sebelumnya yakni untuk menambah wawasan santri tersendiri. Juga dengan pelayanan perpustakaan tersebut, pustakawan memiliki wawasan tentang perpustakaan, kepribadian yang ramah, luwes dan menarik, juga memiliki tehnik komunikasi yang baik. Dengan itu para pembaca akan meresa nyaman dengan perbaikan pengelolaan dalam manajemen perpustakaan Az-zainiyah Pondok Pesantren Nurul Jadid.

D. Kesimpulan

Dari pembahasan Implementasi Continous Quality Improvement dalam manajemen perpustakaan di Az-zainiyah pondok Pesantren Nurul Jadid disimpulkan bahwa:

\footnotetext{
${ }^{13}$ HM Mansyur, Manajemen Perpustakaan Sekolah, Jurnal Pustakalola, Vol 7:1, 2015, 52. Diakses Pada Tanggal 2 Mei 2018.
} 
1. Terdapat lima macam jenis perpustakaan yakni: perpustakaan Nasional, perpustakaan umum, perpustakaan khusus, perpustakaan sekolah dan perpustakaan perguruan tinggi.

2. Implementasi Continous Quality Improvement dalam manajemen perpustakaan Az-zainiyah yakni pengelolaannya disesuiakan dengan kebutuhan yang terdapat di wilayah Az-zainiyah Pondok Pesantren Nurul Jadid idealnya layanan yang biasa dilakukan diantaranya: Gedung atau ruangan, peralatan dan perlengkapan, tata ruang perpustakaan, koleksi bahan pustaka, tenaga perpustakaan, biaya, pelayanan perpustakaan, Tata tertib perpustakaan.

3. Setelah dilakukannya analisis, maka terjadinya pengelolaan pada perpustakan Az-zainiyah Pondok Pesantren Nurul Jadid, banyak menarik minat santri untuk membaca dengan banyak koleksi bahan pustaka untuk meningkatkan wawasannya. 


\section{DAFTAR RUJUKAN}

Marlini Winda sari, Penerapan Fungsi Manajemen Dalam Penegelolaan Perpustakaan Di SMK Tamansiswa Padang, Jurnal Informasi Perpustakaan Dan Kearsipan vol.1 No. 1 September 2012, Seri A, Diakses Pada tanggal 3 Mei 2018

Widiasa I Ketut, Manajemen Perpustakaan Sekolah, Jurnal Perpustakaan Sekolah, Diakses Pada Tanggal 3 Mei 2018

Rokan M. Reza, Manajemen Perpustakaan sekolah, Jurnal Iqra' Volume 11 No 01, Diakses Pada Tanggal 3 Mei 2018

Luthfiyah Fitwi, Manajemen PerpustakaanDalam Meningkatkan Layanan Perpustakaan, Jurnal el-Idare, vol.1, No.2, Diakses Pada tanggal 2 Mei 2018

Wikipedia. 2012. Definisi Perpustakaan. www.wikipedia.com diakses pada tanggal 2 Mei 2018.

https://sites.google.com/site/seputarilmuperpustakaan/jenis-jenis-perpustakaan. diakses pada tanggal 2 Mei 2018.

M Muhammad Kharits, Pengelolaan Perpustakaan Sebagai Sumber Belajar di Sd Negeri 1 Pogung Kecamatan Cawas Kabupaten Klaten, Artikel Jurnal 2015, 4-8. Diakses Pada 2 Mei 2018.

Alrosyid Hafid, Pengadaan Bahan Pustaka di Perpustakaan Universitas Muhammadiyah Surakarta, Tugas Akhir, Surakarta: 2008, 28. Diakses Pada Tanggal 2 Mei 2018.

Anugrahangraini, Sistem Pengelolaan Bahan Pustaka, Skripsi, Makasar, 2015, 23-26. Diakses pada tanggal 2 Mei 2018.

Ma'sum Muhammad Kharits, Pengelolaan Perpustakaan Sebagai Sumber Belajar di SD Negeri 1 Pogung Kecamatan Cawas Kabupaten Klaten, Skripsi, Yogyakarta, Januari, 35. Diakses pada tanggal 2 Mei 2018.

Mundiri, A. (2012). PENDIDIKAN TEKNOHUMANISTIK BERBASIS CORE ETHICAL VALUES. At-Tajdid, 1(1), 37-47. 
Mundiri, A. (2015). KOMITMEN ORGANISASIONAL SUMBER DAYA MANUSIA DALAM MENINGKATKAN MUTU PENDIDIKAN PESANTREN. Pedagogik, 3(1), 88-105.

Mundiri, A. (2016). THE LEADERSHIP OF HEADMASTER IN BUILDING A WORK CULTURE BASED ON PESANTREN. In International Conference on Education and Training (pp. 1-7). Malang: Faculty of Education State University of Malang.

Mundiri, A. (2017). Organizational Culture Base On Total Quality Management In Islamic Educational Institution. ADRI International Journal Of Islamic Studies and Social Sciences, 1(1), 1-11.

Mundiri, A., \& Zahra, I. (2017). Corak Representasi Identitas Ustadz dalam Proses Transmisi Pendidikan Karakter di Pesantren. Jurnal Pendidikan Islam, Vol. 2, No, 21-35.

Rochmah Erma Awalien, Pengelolaan Layanan Perpustakaan, Jurnal Ta'allum, Vol 4:2, 2016, 283. Diakses Pada Tanggal 2 Mei 2018.

Mansyur HM, Manajemen Perpustakaan Sekolah, Jurnal Pustakalola, Vol 7:1, 2015, 52. Diakses Pada Tanggal 2 Mei 2018. 